\title{
Assessment of Instructional Supervision Practices at Efutu Circuit in the Cape Coast Metropolis
}

\author{
Ebenezer Kobina Mensah $^{1 *} \quad$ Michael Boakye-Yiadom ${ }^{2}$ \\ 1.MPhil Graduate, Department of Guidance and Counselling, University of Cape Coast; Ghana \\ 2.Research Fellow, Institute for Educational Planning and Administration, University of Cape Coast; Ghana
}

\begin{abstract}
The study aimed at assessing the state of instructional supervision at Efutu Circuit. The study adopted a descriptive survey design and mainly used a questionnaire to obtain data from participants. A sample size of 80 was used for the study. The study revealed that instructional supervisors conduct impromptu visits and class observation only when there is the need. However, little clinical supervision is practiced to support teachers, democratic sharing in an attempt to solve instructional challenges and monitoring of instruction through lessons monitoring tool and syllabus coverage monitoring tool. The study further showed that teachers demonstrate varied attitudes towards instructional supervision which are negative. Their perceptions are that the current supervision is more or less "looking for errors, the current supervision is authoritative rather than democratic, the current supervision is inspection rather than a collaborative process, the current supervision involves a lot of processes that are time consuming as well as the current supervision support us to improve teaching. From the study findings, it was recommended that headteachers should be prompt in supervision of instruction (conduct regular classroom observation) and not only do it when there is need. Also, they need to increase the practice of clinical supervision. Keywords: assessment, instructional, supervision practices, headteachers, circuit
\end{abstract}

DOI: $10.7176 / \mathrm{JEP} / 10-31-04$

Publication date: November $30^{\text {th }} 2019$

\section{Introduction}

The greatest need of instructional leaders of this century is expeditious conformity with instructional practices that will fast-track healthy and productive school environment. Cloud (2010) encapsulates it that in order to ensure a healthy and sustainable communities, we need to apply an ever-expanding body of knowledge, employ an everchanging set of skills; and develop the attitudes that are most likely to create favourable conditions for us to thrive in the constantly metamorphosing age.

Mills (1997) asserted that supervision has direct effect on staff and students' performance. Supervisors assign task and clear responsibilities of performing those tasks and they in turn expects accuracy and punctuality from as signees. It is important that staff performance are constantly monitored and reviewed for it to be abreast with changes and developments. Kankam (2013) indicates that the emergence of the information and knowledge-based society has brought a change of mindset in learning and that new approaches to learning necessitate new approaches to teaching which challenge the teacher's role as a facilitator of learning. For teachers to maintain a continuous development in their profession they must undertake a lot of effective professional activities either individually or in groups through professional development strategies including study groups, peer-coaching, action research, mentoring, teaching portfolios, team teaching, and in-service training (Hismanoglu \& Hismanoglu, 2010). In order for educational institutions to achieve their goals, a mechanism for continuous evaluation of the activities of the institutions, especially, in the instructional process must be put in place.

Aguba (2009) postulated that instructional supervision ensures quality assurance in education which aims at preventing quality problems and ensures that the products of the system conform to the expected standards. Aguba further notes that instructional supervision is basically concerned with supporting and assisting teachers to improve instructions through changing their behaviour. Newstrom and Bittel (2002) state that the purpose of supervision is not to find fault or to punish, but rather to work cooperatively with the teacher. Thus, supervision as the element of the administrative process is concerned with efforts to guide the day-to-day activities of the work group by stimulating, directing and coordinating the workers and their efforts.

Over the years the Monitoring and Evaluation Division of the Ministry of Education has been responsible for the assessment, evaluation and supervision of educational system in Ghana, and considering the decentralization policy, the function of the external supervision was assigned to the District, Municipal and/or Metropolitan Education Directorates. This function has since been carried out by supervisors and inspectors who have the essential duty of putting educational policies into practice, and ensuring that these policies and practices conform to policies and regulations approved by the government through the Ministry of Education (MOE) and the Ghana Education Service (GES) (Appiah, 2009). These supervisors and inspectors visit schools and classrooms to see the teachers at work, hold occasional conferences with teachers and write reports to the irrespective District, Municipal and/or Metropolitan Education Directorates. According to Kpatakpa (2008) there is a wide spread feeling that academic standards are fast falling and the blame is shifted to the teacher, who is seen not to be providing effective 
teaching and learning. What then might have gone amiss to affect the performance of the teachers so much so that their performances affect negatively the general output of pupils in the schools? The challenge is placed at the doorpost of "effective supervision" (p. 24).

Instructional supervision is normally understood to mean the formal process of professional support accorded to practitioners to enable them develop knowledge, competence and assume responsibility for their own practice. It is the process of helping, guiding and mentoring a teacher with the sole purpose of improving their delivery of classroom instruction and consequently student learning. It is an intervention that is provided by a senior member of a profession to a junior member(s) of that profession with the intention of enhancing professional functioning of the junior member(s) (Bernard \& Goodyear, 1998). Through supervision of instruction, "the supervisors assist in improving classroom instructions because teachers are made more competent and efficient, parent are satisfied with the performance of their children, children are motivated to work harder in order to achieve the required standard; hence in the long run, the goal of education is achieved." (Ebele \& Olofu, 2017, p.80).

\subsection{Statement of the Problem}

As the time passed, the changes in globalisation certainly affected the education field that requires careful planning, systematic and holistic approaches in order to face the future education challenges (Mohd, Zuraidah, Nik, Mohd, \& Norhesham, 2014). So, it is warrant for educators and all stakeholders to collaborate in effort to enhance the style and quality of our educational model. Moreover, the quality of the teacher's instruction and the level of student learning are heavily dependent on the constant and continuous school-based supervision. To realise this, the instructional leaders must engage the teachers in a manner that is bound to improve practice and inspire them to be creative and knowledgeable. However, the question that always lingers is the invaluableness of principals' supervisory practices and the regularity of the supervision.

Even though many new approaches have been worked out to enhance teaching and learning in schools, the public outcry about the academic performance of pupils as well as the general standard of education of public basic schools in the country is said to be on the decline. Stakeholders and many parents have blamed this state of affairs on the lack of commitment by administrators of schools and poor performance of teachers. Consequently, across session of people in the Metropolis argue out that supervision in the schools has not seen the expected changes. There has been a public outcry on this pertinent issue and therefore has necessitated for an investigation. The big question then is, does proper supervision go on in the schools?

An observation made suggest the conduct of teachers within Efutu Circuit has not been the best. Many people have expressed their grievances and complaint on the teachers' misconducts. More so, the performance of students of Basic Schools in the Efutu Circuit has left a lot to be desired. If teachers' conduct affects students' performance, then one can supposedly blame teachers on the average performance of the students. Although records of action plans, monitoring and follow up reports show that supervision goes on within the Basic Schools in the Efutu Circuit, the effect does not seem to show in the work life of the staff and students' performance. It is against this backdrop that this study was conducted to assess instructional supervision practices at Efutu Circuit of Cape Coast Metropolis in the Central Region.

\subsection{Research Objectives}

The following research objectives guided the study to:

1. Determine the instructional supervision practices used by the supervisors in the Efutu Circuit in the Cape Coast Metropolis.

2. Investigate teachers' attitudes towards instructional supervision in the Efutu Circuit in the Cape Coast Metropolis.

3. Examine the challenges associated with supervision of instruction Efutu Circuit in the Cape Coast Metropolis.

\section{Research Methods}

This section discussed of the method and procedures used in the study. The following are discussed: research design, population, sampling procedure and data collection instrument used in the data collection. Also, administration of the instrument and the procedure for data processing and analysis are also presented.

\subsection{Research Design}

The descriptive survey design was adopted for this study. According to Ary, Jacobs, and Razavieh (1990), the descriptive survey is useful for this type of survey because it attempts to collect data from members of a population in order to determine the current status of that population. This design enabled the researcher to obtain accurate information about specific characteristics of a phenomena. In the view of Mensah (2019), descriptive design deals with the conditions that occurs, such as determining the nature of the prevailing conditions, practices and attitudes; opinions that are held; processes that are going on; or trends that are developed. This design was used because it 
enabled the participants expressed their opinions on instructional supervision at Efutu Circuit in the Cape Coast Metropolis.

\subsection{Population}

Population as used in this study refers to the people with common characteristics that the researcher decided to involve in the study. The target population of the study was all basic school teachers at Efutu Circuit in the Cape Coast Metropolis. There were eleven (13) basic schools in the Efutu Circuit. Out of these school six (6) served as the accessible population. The estimated accessible population was 99 teachers.

\subsection{Sampling Procedure}

The simple random sampling technique was used to select participants. The lottery method was used whereby the names of teachers were written on slips of papers, folded and mixed in a bowl. Participants were drawn with replacement from the bowl until the require sample size was obtained. A sample size of 80 was selected for the study based on Krejcie and Morgan's (1970) table of sample size determination.

\subsection{Data Collection Instrument}

The study used questionnaires to obtain data from participants. We designed the questionnaire and it contained fourteen (14) items. The items on the questionnaire were developed based the literature review on the research objectives guiding the study. The instrument was content validated by two expert from the Institute for Educational Planning and Administration in the University of Cape Coast. We pilot-tested the questionnaire on 10 teachers at two schools in the Bakaano Circuit. The reliability estimate of the instrument was 0.94 using the Cronbach's alpha.

\subsection{Data Procedure}

We visited the selected schools to sought permission from the headteacher and then arranged for convenient day and time for the administration of the questionnaire. During the administration, the participants were briefed on the objectives of the study and the need to respond frankly to the items. The items were then distributed to them. The participants' concerns were addressed after which they were given time to respond to the items.

\subsection{Data Analysis and Processing}

Data obtained were analysed by using research questions. Descriptive statistical tools, namely, frequencies and percentages were used to answer research questions 1 to 3 . The responses that were obtained from the data collection process were coded from 1-2 for worded items from 'Agree' to 'Disagree' to determine their direction. This indicated the relative standing of the individuals items on the dimensions of their views on the instrument after which individual item frequency distribution were calculated.

\section{Results}

Research Objective One sought to determine instructional supervision practices used by the supervisors in the Efutu Circuit. The data obtained from the respondents were analysed using percentages and frequencies. The results are presented in Table 1.

Table 1. Instructional Supervision Practices

\begin{tabular}{|l|l|l|l|l|}
\hline Statement & \multicolumn{2}{|c|}{ Agree } & \multicolumn{2}{|c|}{ Disagree } \\
\hline & Freq & $\%$ & Freq & $\%$ \\
\hline Class observation is done only when there is need. & 65 & 81.3 & 15 & 18.7 \\
\hline $\begin{array}{l}\text { Supervisors monitor instruction through lessons monitoring tool and syllabus } \\
\text { coverage monitoring tool. }\end{array}$ & 35 & 43.8 & 55 & 56.2 \\
\hline Instructional supervisors conduct impromptu visits. & 70 & 87.5 & 10 & 12.5 \\
\hline $\begin{array}{l}\text { Supervisors allow for a democratic sharing in an attempt to solve instructional } \\
\text { challenges. }\end{array}$ & 34 & 42.5 & 56 & 57.5 \\
\hline Clinical supervision is practiced to support teachers & 31 & 38.7 & 49 & 61.3 \\
\hline
\end{tabular}

Table 1 shows the instructional supervision practices exhibited by the supervisors as indicated by participants. The majority (70) of the participant representing $87.5 \%$ responded positively with 'Agree' to the 'instructional supervisors conduct impromptu visits'. There were $65(81.3 \%)$ of the participants who responded positively with an 'Agree' response for the statement 'class observation is done only when there is need'. However, the statement 'clinical supervision is practiced to support teachers' recorded 31 (38.7\%) responses for 'Agree'. Similarly, the statement 'supervisors allow for a democratic sharing in an attempt to solve instructional challenges' also recorded $34(42.5 \%)$ responses for '. Again, the statement 'Supervisors monitor instruction through daily lessons monitoring tool and syllabus coverage monitoring tool' recorded 35 responses of 'Agree' representing 43.8\%. The implication of these findings is that instructional supervisors conduct impromptu visits and class observation only when there is the need as supervision practices. However, less is done to Clinical supervision is practiced to support teachers, 
democratic sharing in an attempt to solve instructional challenges and monitoring of instruction through lessons monitoring tool and syllabus coverage monitoring tool. The researcher is in agreement with the participants.

Research Question Two sought to determine instructional supervision practices used by the supervisors in the Efutu Circuit. The data obtained from the respondents were analysed using percentages and frequencies. The results are presented in Table 2.

Table 2. Teachers Attitude towards Instructional Supervision

\begin{tabular}{|l|l|l|l|l|}
\hline Statement & \multicolumn{2}{|c|}{ Agree } & \multicolumn{2}{|c|}{ Disagree } \\
\hline The current supervision involves a lot of processes that are time consuming. & Freq & $\%$ & Freq & $\%$ \\
\hline The current supervision is more or less "looking for errors" & 56 & 70 & 24 & 30 \\
\hline The current supervision is authoritative rather than democratic & 74 & 92.5 & 6 & 7.5 \\
\hline The current supervision is inspection rather than a collaborative process & 69 & 86.3 & 11 & 13.7 \\
\hline The current supervision support us to improve teaching & 64 & 80 & 16 & 20 \\
\hline
\end{tabular}

Table 2 shows the attitude of teachers towards instructional supervision as indicated by participants. The majority (74) of the participants representing $92.5 \%$ responded positively with 'Agree' to the statement 'the current supervision is more or less "looking for errors". There were $69(86.3 \%)$ of the participants who responded positively with an 'Agree' response for the statement 'the current supervision is authoritative rather than democratic'. Similarly, the statement 'the current supervision is inspection rather than a collaborative process' recorded 64 (80\%) responses for 'Agree'. Furthermore, the statement 'the current supervision involves a lot of processes that are time consuming' also recorded 56 (70\%) responses for 'Agree'. Again, the statement 'the current supervision supports us to improve teaching' recorded 54 responses of 'Agree' representing 67.5\%. The implication of these findings is that teachers demonstrate varied attitude towards instructional supervision. These include the current supervision is more or less "looking for errors, the current supervision is authoritative rather than democratic, the current supervision is inspection rather than a collaborative process, the current supervision involves a lot of processes that are time consuming as well as the current supervision support us to improve teaching.

Research Question Three sought to determine challenges hindering instructional supervision practices at the Efutu Circuit. The data obtained from the respondents were analysed using percentages and frequencies. The results are presented in Table 3.

Table 3. Instructional Supervision Challenges

\begin{tabular}{|l|l|l|l|l|}
\hline Statement & \multicolumn{2}{|c|}{ Agree } & \multicolumn{2}{|c|}{ Disagree } \\
\hline & Freq & $\%$ & Freq & $\%$ \\
\hline The supervisor's personality & 67 & 83.8 & 13 & 16.2 \\
\hline There is inadequate time to conduct thorough supervision of instruction & 78 & 97.5 & 2 & 2.5 \\
\hline Teachers' fear of supervision as a result criticism from supervision & 64 & 80 & 16 & 20 \\
\hline Inadequate resources for the supervision of teaching and learning activities. & 75 & 93.8 & 5 & 6.2 \\
\hline
\end{tabular}

Table 3 shows the challenges hindering instructional supervision practices as indicated by participants. The majority (78) of the participants representing 97.5\% responded positively with 'Agree' to the statement 'there is inadequate time to conduct thorough supervision of instruction'. There were $75(93.8 \%)$ of the participants who responded positively with an 'Agree' response for the statement 'inadequate resources for the supervision of teaching and learning activities'. Similarly, the statement 'the supervisor's personality' recorded 67 (83.8\%) responses for 'Agree'. Furthermore, the statement 'teachers' fear of supervision as a result criticism from supervision' also recorded $64(80 \%)$ responses for 'Agree'. The implication of these findings is that certain factors hinders effective instructional supervision practices. These challenges include inadequate time to conduct thorough supervision of instruction, inadequate resources for the supervision of teaching and learning activities, the supervisor's personality and teachers' fear of supervision as a result criticism from supervision.

\section{Dicussion}

This section summarises and discusses the research result with, an attempt to integrate the results into existing literature. The study revealed that instructional supervisors conduct impromptu visits and class observation only when there is the need as supervision practices. However, less is done to Clinical supervision is practiced to support teachers, democratic sharing in an attempt to solve instructional challenges and monitoring of instruction through lessons monitoring tool and syllabus coverage monitoring tool. The findings of the current is in line with the findings of Appiah (2009) that supervisors and inspectors visit schools and classrooms to see the teachers at work, hold occasional conferences with teachers and write reports to their respective District, Municipal and/or Metropolitan Education Directorates. The researcher further indicated that they do these by demonstrating different approaches with regards to impromptu visit and as they have a schedule time for supervision exercise. On the hand, the findings of the study contradict the findings of Esia-Donkoh and Baffoe (2018) that most basic schools are 
practicing clinical supervision in which work with teachers in a collaborative way, and provide expert assistance to teachers with the view of improving instruction in the classroom. The implication of this findings is that the type of instructional supervision practiced need to be reviewed to meet the clinical practices to make teachers responsible who are able and willing to evaluate their own instruction, accept criticism and use it for change.

Furthermore, the study showed that teachers demonstrate varied attitude towards instructional supervision. These include the current supervision is more or less "looking for errors, the current supervision is authoritative rather than democratic, the current supervision is inspection rather than a collaborative process, the current supervision involves a lot of processes that are time consuming as well as the current supervision support us to improve teaching. The current findings corroborate with the findings of Gwaradzimba and Shumba (2010) that achieving educational aims and providing quality basic education greatly depends on the significant role played by teachers in determining the nature of supervision as a result of their attitude. To Gwaradzimba and Shumba, a teacher with a negative attitude towards instructional may not encourage effective clinical supervision in schools. Similarly, the findings are in line with findings of Esia-Donkoh and Baffoe (2018) that the kind of attitude teachers display great influences supervision practices. It should be noted with great concern that the way teachers gain professional support from instructional supervisors and the way teachers view and think about instructional supervision process is very important in determining the outcomes of the supervision process.

Again, the study revealed that certain factors hinders effective instructional supervision practices. These challenges include inadequate time to conduct thorough supervision of instruction, inadequate resources for the supervision of teaching and learning activities, the supervisor's personality and teachers' fear of supervision as a result criticism from supervision. The findings of the study agree with the findings of Okendu (2012) that instructional supervision is challenge with resources in terms of time and money to purchase appropriate materials for supervisory practices. In a similar vein, the findings validate the findings of Sergiovanni (2009) that clinical supervision is faced with a number challenges which reduce it effectives. These challenges are the personality of the supervisor, time factor and fear of criticism on the part of teachers who sometimes see supervision as oppression and error pointing instead of assisting them. For supervision to be effective logistics must be provided to support it. No wonder work slows down and sometimes deadlines are not met.

\section{Conclusion}

Instructional supervision requires the principal to conduct a closer, periodic and continual internal supervisory practice in order to ensure that the school meets its goals. Establishing mutual trust with the teachers and positive learning environment is paramount if success is to be realized in the whole process. The fact that the headteachers often made use of little supervisory practices, is an indication that they were unaware of the benefits of clinical supervisory practices they had to undertake to ensure effective teaching and learning in their various schools.

\subsection{Implications for Practice}

From the findings and conclusion, ssupervisors and the supervision directorate of Ghana Education service needs to pay greater attention to the form of supervision which need to be exhibited at various basic schools in Ghana. This will help fill the gap of inadequate supervision process whereby supervisors employ the classical method. The supervisory practices need to be looked at and clearly outlined to guide supervisors in their daily activities. Basic school administrators need not to rely on government subventions but appeal to the general public for support in terms of resources needed for effective teacher supervision.

\subsection{Recommendations}

Based on the findings, conclusion and implications for practice, the following recommendations are made:

1. The headteachers at the Efutu Circuit should be prompt in supervision of instruction (conduct regular classroom observation) and not only do it when there is need.

2. The quality assurance team through Cape Coast Metropolitan Director of Education should organise training programmes for headteachers as well as teachers on the need for effective and contemporary instructional supervision practices. They should also be regular in their supervision.

3. Headteachers at the Efutu Circuit should embrace clinical supervision to foster collaboration with teachers to improve students' leaning achievements.

\section{References}

Aguba, C. R. (2009) Educational Administration and Management: Issues and Perspectives. Enugu, Nigeria: Tons and Tons PDS Publishers.

Appiah, M. R. (2009) A Study of Supervision in Rural and Urban Junior High Schools in the Akuapim-North District. [Online] Available: http://www.ir.ucc.edu.gh/dspace/bitstream/123 456789/..../APPIAH\% 202009\%202.pdf.

Ary, D., Jacobs, L. C., \& Razavieh, A. (1990) Introduction to Research in Education (4th ed.). Forth-Worth, Holt: 
Rinehart and Winston Inc.

Bernard, J., \& Goodyear, R. (1998). Fundamentals of Clinical Supervision (2nd ed.). Needham Heights, MA: Allyn and Bacon.

Cloud, J. (2010) Educating for a Sustainable Future. In H. H. Jacobs (Ed.). Curriculum 21: Essential Education for a Changing World (pp. 7-17). Alexandria: ASCD Publications.

Ebele, U., \& Olofu, P. (2018) "Enhancing the Standard of Teaching and Learning in the 21st Century via Qualitative School-based Supervision in Secondary Schools in Abuja Municipal Area Council (AMAC)", International Journal of Educational Administration and Policy Studies, 9(6), 79-83.

Esia-Donkoh, K., \& Baffoe, S. (2018) "Instructional Supervisory Practices of Headteachers and Teacher Motivation in Public Basic Schools in Anomabo Education Circuit", Journal of Education and e-Learning Research, 5(1), 43-50.

Gwaradzimba, E., \&. Shumba, A. (2010) "The Nature, Extent and Impact of the Brain Drain in Zimbabwe and South Africa.", Acta Academica, 24(1), 209241.

Hismanoglu, M., \& Hismanoglu, S. (2010) "English Language Teachers' Perceptions of Educational Supervision in Relation to their Professional Development: A Case Study of Northern Cyprus", Novitas-ROYALS (Research on Youth and Language), 4(1), 16-34.

Kankam, G. (2013) Creating Synergies and Promoting Professional Development Practices in the Faculty of Educational Studies, University of Education, Winneba. A Paper Delivered at a 2-day (26th - 27th May, 2013) Faculty retreat at Manna Height Hotel, Mankessim, Ghana.

Kpatakpa, E. (2008) Supervision of Basic School Teachers in Jasikan District. [Online] Available: http://www.ir.ucc.edu.gh/dspace/bitstream/123456789//KPATAKPA\%202008.pdf.

Krejcie, R. V., \& Morgan, D. W. (1970) "Determining Sample Size for Research Activities", Educational and Psychological Measurement, 30, 607-610.

Marion, S., DePascale, C., Domaleski, C., Gong, B., \& Diaz-Biello, E. (2012) Considerations for Analyzing Educators' Contributions to Student Learning in Non-Tested Subjects and Grades with a Focus Oon Student Learning Objectives. Dover, NH: Center for Assessment.

Memduhoglu, H. B. (2012) "The Issue of Education Supervision in Turkey in the Views of Teachers, Administrators, Supervisors, and Lecturers", Educational Sciences' Theory and Practice, 12(1), 149-156.

Mensah, E. K. (2019) "Assessing Multicultural Competence of Counsellors in Public Universities in Ghana", Journal of Education and E-Learning Research, 6(3), 142-148. httpdoi.org/10.20448/journal.509.2019.63.142.148.

Mills, D. Q. (1997). Real power to the people. Management Development, 2, 87-89.

Newstrom, J. W., \& Bittel, L. R. (2002) Supervision: Managing for Results (8th ed). New York, NY: Glencoe McGraw-Hill.

Okendu, J. N. (2012) "The Influence of Instructional Process and Supervision on Academic Performance of Secondary School Students of River State, Nigeria”, Academic Research International Journal, 3(1), $147-$ 151

Sergiovanni, T. J. (2009) The Principalship: A Reflective Practice Perspective. Boston, MA: Pearson Educational Inc.

Sergiovanni, T. J., \& Starratt, R. J. (2002) Supervision: A Redefinition (7th ed.). New York, NY: McGraw Hill.

Mohd, R. T., Zuraidah, A., Nik, M. M., Mohd, R.Y., \& Norhesham, M. J. (2014) “Clinical Supervision of Teaching Mara Junior Science College (MJSC), Malaysia”, Procedia - Social and Behavioral Sciences, 191, pp.452458. 